\title{
A violência da escola na voz de futuros professores: uma probabilidade da produção da cultura da violência em ambientes escolares? ${ }^{1}$
}

\section{The school violence in the voice of future teachers: a probability of production of culture of violence in school environments?}

\author{
Marilda da Silva ${ }^{2}$
}

\begin{abstract}
RESUMO
O objetivo desta pesquisa é mostrar os tipos de violência cometidos por professores que foram testemunhados e/ou vivenciados por futuros professores durante sua história de escolarização. Trata-se de uma pesquisa quanti-qualitativa cuja forma é descritivo-analítica. A coleta, organização e análise de dados foram procedidas por meio da Análise de Conteúdo (BARDIN, 1977). A conceituação foi triangulada a partir de Bernard Charlot, Pierre Bourdieu e do Relatório do Núcleo de Estudos da Violência da Universidade de São Paulo (NEV/USP) (CARDIA, 2012). Os sujeitos são 12 alunos que, em 2011, cursavam a licenciatura em Pedagogia na Faculdade de Ciências e Letras - Campus de Araraquara - Universidade Estadual Paulista (UNESP). A grande maioria do grupo de sujeitos afirmou ter testemunhado ou vivenciado violência por parte de professores durante sua formação básica. Segundo esses sujeitos, os tipos de violência mais recorrentes são de natureza simbólica. Eles frequentaram, não igualmente, o sistema público de ensino e o sistema privado. A violência, sobretudo simbólica, ocorreu nos dois sistemas de ensino. Portanto, trata-se de um fenômeno que atinge diferentes frações de classes. Levando em conta que os sujeitos deste estudo são futuros professores, estabeleceu-se relação com a noção de "ciclo de abusos" e "produção da cultura da violência", tendo
\end{abstract}

${ }^{1}$ A presente pesquisa é financiada pela Fundação de Amparo à Pesquisa do Estado de São Paulo (FAPESP) por meio dos processos n ${ }^{\circ}$ 2010/11054-6 e no 2012/04119-0.

${ }^{2}$ Universidade Estadual Paulista Júlio de Mesquita Filho, Faculdade de Ciências e Letras de Araraquara. Rodovia Araraquara-Jaú Km 1. Araraquara, São Paulo, Brasil. CEP: 14800-901. 
em vista o futuro exercício docente do grupo em questão. Busca-se, aqui, compreender a complexidade do fenômeno da violência em meio escolar e não estabelecer um jogo entre culpados e inocentes. Tampouco estabelecer estigmas indissociáveis, ou não, sobre a violência da escola.

Palavras-chave: violência; escola; professor; aluno.

\begin{abstract}
The purpose of this research is to show the types of violence committed by teachers that were experienced and/or witnessed by future teachers during their schooling history. It's a quantitative and qualitative research. The collection, organization, and analysis of data proceeded from Content Analysis (BARDIN, 1977) and the construction of Bernard Charlot and Pierre Bourdieu's works and specific literature on the theme. The subjects are 12 students that attended the Pedagogy undergraduate program in 2011 at the Faculty of Science and Arts of the city of Araraquara in the state of São Paulo, Brazil. The data shows that the majority of the group of individuals claimed to have witnessed or experienced violence by teachers during their basic training. According to them, among the most recurring types of violence are those of symbolic nature. They attended, not equally, the public system and the private system. This enabled pointing out that violence, especially symbolic violence, occurred in both school systems. Therefore, this is a phenomenon that affects different fractions of social classes. Considering that the participants of this research are future teachers, it was established a relation with the notion of 'cycle of abuse', since there is a high possibility of them practicing the teaching function.
\end{abstract}

Keywords: violence; school; teacher; student.

\title{
Introdução
}

Este artigo derivou do projeto de pesquisa intitulado Violência por professores e professoras na voz de suas vítimas: uma estrutura do habitus profissional em professores brasileiros financiado pela FAPESP processos $\mathrm{n}^{\circ}$ 2010-11054-6 e $n^{\text {o }}$ 2012/04119-0. O objetivo desta pesquisa é mostrar os tipos de violência cometidos por professores que foram testemunhados e/ou vivenciados por futuros professores durante sua história de escolarização, tendo em vista os malefícios que isso traz para a futura docência desses sujeitos. O objetivo deste estudo não é encontrar algozes e vítimas. Nosso interesse é apresentar sem moralismos, corporativismos e reduções a complexidade do fenômeno da violência em meio 
escolar. Levando em conta a ordem de grandeza e a gravidade da violência cometida por uns e por outros no âmbito da escola, temos de enfrentar para melhoria dessa instituição e da sociedade o fenômeno em questão em todas as suas faces: violência de alunos contra professor e violência de professor contra alunos. Gostaríamos muito que este artigo fosse lido de modo despretensioso, sem julgamentos e sem perder de vista a dificuldade de enfrentamento da violência como um todo e da violência da escola em especial, em nosso país e em qualquer outro.

Levando em conta que esta pesquisa trata-se de violência em meio escolar, buscamos em Bernard Charlot (2002) a contribuição analítica. Em seus estudos, esse autor apresenta três categorias explicativas para o fenômeno. São elas: a) violência na escola; b) violência à escola; e c) violência da escola. A primeira categoria, violência na escola, distingue-se em especificidade das outras duas. Segundo Charlot (2002), esse tipo de violência é descrito como sendo uma violência constituída fora da escola e a escola funciona somente como local de sua objetivação, ou seja, não é um fenômeno produzido pela e na escola, ele é apenas manifestado na instituição pelas partes envolvidas. As outras duas categorias têm algo em comum: a violência é constituída na instituição. A violência à escola diz respeito às ações de caráter violento cometidas pelos alunos contra os diferentes profissionais da escola e contra a própria instituição. No que se refere à categoria "violência da escola", o agressor e o agredido invertem-se. Trata-se da violência cometida pela instituição escolar por meio dos mais diferentes mecanismos institucionais e cometida por professores contra alunos. Portanto, neste estudo a categoria nuclear é a "violência da escola" cometida por professores contra alunos.

No que diz respeito à tipologia da violência no interior de cada categoria, quem nos auxiliou foi Pierre Bourdieu (2011). Esse autor, especificamente nessa obra referida, apresenta largas explicações sobre poder, poder simbólico e como esses "poderes" são operacionalizados em sociedades cujo modus operandi é o capitalista. O que está em jogo é a força que o poder simbólico tem sobre e nos agentes sociais. Nessa medida, conscientemente ou não, os próprios agentes se valem - ou necessitam para se valer - de procedimentos simbólicos. Segundo ele,

O poder simbólico é um poder de construção da realidade que tende a estabelecer uma ordem gnosealógica: o sentido imediato do mundo (e, em particular, do mundo social) supõe aquilo a que Durkeim chama o conformismo lógico, quer dizer, "uma concepção homogénea do tempo, do espaço, do número, da causa, que torna possível a concordância entre as inteligências" (BOURDIEU, 2011, p. 9). 
O excerto acima deixa claro que os "procedimentos simbólicos" são poderosos no que diz respeito à homogeneização de ações, de valores, de atitudes legitimadas socialmente. Justamente por isso que a lógica do poder simbólico foi-nos bastante útil neste estudo, pois a violência em meio escolar, os dados abaixo explicitarão, é produzida na maioria das vezes pelo que estamos denominando "procedimentos simbólicos". Isto é, fatos suspeitos ocorrem livres do véu da suspeitabilidade. Vale dizer que a ideia de "poder" é bastante adequada quando se trata da relação professor/aluno. Bourdieu (2011) explica, ainda, que sistemas simbólicos, para ele, constituem instrumentos estruturantes que, neste caso, são eficazes na legitimação da dominação. O que vai diretamente ao encontro das relações sociais estabelecidas na sala de aula entre aluno e professor. Para nosso autor:

O poder simbólico é um poder que aquele que lhe está sujeito dá àquele que o exerce, um crédito com que ele o credita, uma fides, uma auctoritas, que ele lhe confia pondo nele a sua confiança. É um poder que existe porque aquele que lhe está sujeito crê que ele existe (BOURDIEU, 2011, p. 188).

Bernard Charlot e Pierre Bourdieu ajudaram na opção sobre a bibliografia específica. Nesse sentido, para concluir a triangulação conceitual, optamos por utilizar o Relatório NEV/USP intitulado Pesquisa nacional, por amostragem domiciliar, sobre atitudes, normas culturais e valores em relação à violação de direitos humanos e violência: Um estudo em 11 capitais de estado coordenado por Nancy Cardia (2012). Essa opção deveu-se, também, por se tratar de um relatório recente que tem a violência de modo geral como sua categoria básica. $\mathrm{O}$ relatório mostra o fenômeno violência em suas diferentes faces, incluindo dados imprescindíveis às reflexões sobre a violência em meio escolar. Interessa-nos muito a compreensão que o relatório explicita sobre a constituição do fenômeno violência:

A abordagem adotada neste estudo é de que a violência é socialmente aprendida. É aprendida em casa - por meio da família e as práticas disciplinares utilizadas pelos pais e/ou aqueles que cuidam da criança, pela observação do modo como os adultos se 
relacionam e lidam com conflitos, pela maneira como os irmãos se relacionam e como usam ou não a violência e agressão para resolverem disputas e competições - e pelo que assistem nos meios de comunicação e na internet. A violência também é aprendida fora da casa pelo que crianças e jovens observam na comunidade, nas escolas, nas instituições e pelas experiências de serem vítimas ou testemunhas de diferentes eventos violentos (CARDIA, 2012, p. 59).

Observe que o Relatório NEV/USP (CARDIA, 2012) é bastante robusto para nosso interesse, porque enfatiza em diferentes momentos que o agente que fica exposto à violência de modo geral pode ser um produtor/reprodutor do fenômeno. Nesse sentido, a violência da escola pode ser, sem sombras de dúvidas, um espelho para seus usuários diretos e indiretos. Levando em conta que os sujeitos deste estudo são futuros professores, a possibilidade desse espelhamento agrega ordem de grandeza nada desprezível. Portanto, insistimos no risco que se corre quando se trata desse tipo de "modelagem": o agente exposto à violência poderá, sim, reproduzi-la quando estiver, sobretudo, na posição do agente que o agrediu. O que poderá concorrer, segundo o relatório, para estimular uma "cultura da violência".

A exposição à violência também afeta as atitudes, os valores e as crenças em relação às causas e ao uso da violência, aumentando a probabilidade de que esta seja encarada como uma reação razoável e apropriada para uma situação, como aceitável para corrigir um erro ou como aceitável para se proteger a honra, estimulando uma "cultura da violência" (CARDIA, 2012, p. 4).

Portanto, a triangulação conceitual deste estudo foi engendrada por meio das ideias de Bernard Charlot (2002) sobre violência da escola, as ideias de Pierre Bourdieu (2011) sobre a operacionalização do poder e do poder simbólico e por meio das ideias/dados do Relatório NEV/USP (CARDIA, 2012). 


\section{Metodologia}

Trata-se de uma pesquisa quanti-qualitativa cuja forma é descritivo-analítica. A coleta, organização e análise de dados procederam-se por meio da Análise de Conteúdo (BARDIN, 1977). O texto-fonte são entrevistas realizadas com 12 futuros professores que, em 2011, cursavam o sexto período da Licenciatura em Pedagogia na Faculdade de Ciências e Letras - Campus Araraquara/ UNESP. O tipo de entrevista foi a semiestruturada, mas sem direcionamento explícito para questões de violência em meio escolar. A pergunta que funcionou como chave para o desenrolar da entrevista foi a seguinte: "quais foram os fatos mais marcantes em sua escolarização?". A intenção de utilizar esse tipo de entrevista está relacionada ao que Bardin (1977) entende sobre as entrevistas não diretivas. Para ela,

A prática de entrevistas não diretivas, por exemplo, torna sensível um discurso de tipo planificado. Tal como numa tela com urdidura e trama, os temas aparecem e depois reaparecem um pouco mais à frente, em função da progressão de um pensamento que se procura. O processo de análise transversal sintética consiste em destruir, com tesoura e cola (ou tratamento de texto), este pequeno jogo do eixo de espírito, mas, aquando da decifração estrutural, é muito instrutivo referenciá-lo (BARDIN, 1977, p. 97).

Assim, as entrevistas foram realizadas mais por meio de uma conversa e menos por meio de indicações estruturais. A estruturação, em casos como esse, é feita a posteriori no momento da descrição/análise. Os entrevistados puderam lembrar e contar memórias de sua escolarização e foi nesse jogo de memória que o tema violência em ambiente escolar foi surgindo, o que possibilitou um acervo de fatos testemunhados e vivenciados pelos sujeitos desta pesquisa. A organização das categorias se deu, de acordo com Bardin (1977), pela localização das unidades de sentido: episódios vividos ou testemunhados durante a história de escolarização. As categorias dizem respeito ao tipo de violência testemunhada e/ou vivenciada em sala de aula, porque a modalidade do fenômeno violência neste estudo é "violência da escola". 


\section{Os dados}

Trata-se de 12 sujeitos: 10 do sexo feminino ${ }^{3}$ e 2 do sexo masculino. Todos estão na faixa etária que vai dos 21 aos 25 anos. São naturais do estado de São Paulo e, no que diz respeito aos sistemas de ensino nos quais construíram sua história de escolarização, temos: 3 sujeitos que estudaram somente em escolas privadas; 4 , somente em escolas públicas; 3 , em escolas públicas e privadas; e 2 que não informaram. Essa é uma informação que permite verificarmos se há diferença no que diz respeito à violência da escola entre o ensino público e o ensino privado. O gráfico abaixo detalha nesse sentido.

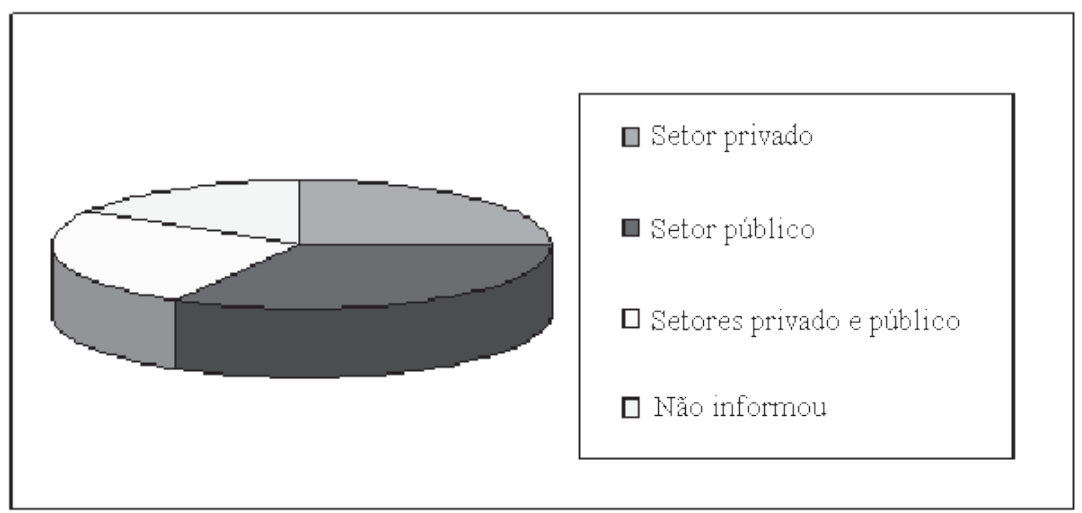

GRÁFICO 1 - SETORES ESCOLARES EM QUE OS SUJEITOS CONSTRUÍRAM SUA HISTÓRIA DE ESCOLARIZAÇÃO

FONTE: A autora.

A maioria dos sujeitos, 7 deles, construiu sua história de escolarização no setor público e no setor privado, sendo 4 deles somente no público e 3 deles no público e no privado ${ }^{4}$. Portanto, podemos dizer que, dos 10 sujeitos que informaram em que setor concluíram a escola básica, $70 \%$ deles em algum momento frequentaram a escola pública e $60 \%$ frequentaram em algum momento a escola privada. Esse dado interessa-nos para pensarmos se o fenômeno "violência

${ }^{3}$ O que não constitui novidade, uma vez que no curso de Pedagogia há o fenômeno da feminização. Sobre ele, dentre outros, tratam os seguintes autores: Demartini e Antunes (1993); Werle (2005); e Rabelo e Martins (2010).

${ }^{4}$ Dois sujeitos não informaram em que setor concluíram a escola básica. 
da escola" é constituído, ou não, nos dois setores de ensino responsáveis pela formação básica em nosso país. Abaixo, por meio dos Gráficos 2 e 3, essa verificação poderá ser ampliada.

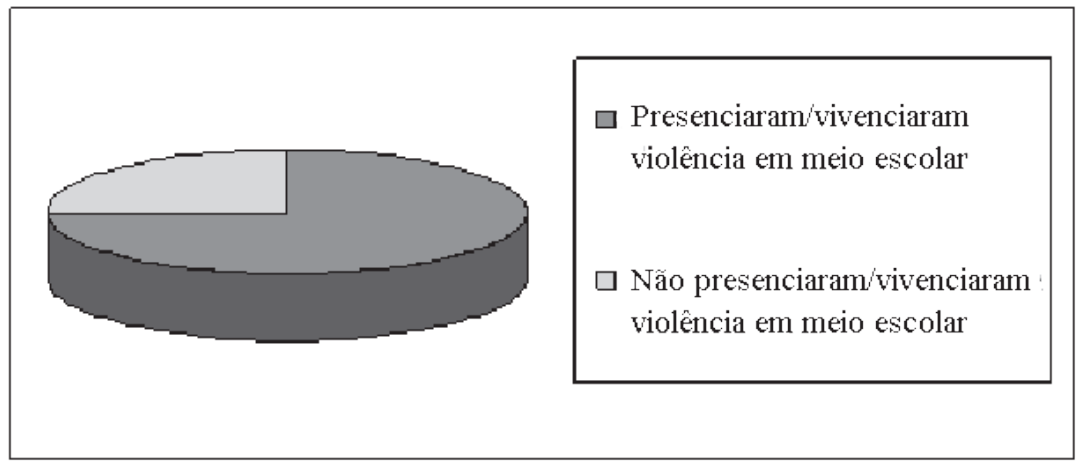

GRÁFICO 2 - SUJEITOS QUE TESTEMUNHARAM/VIVENCIARAM VIOLÊNCIA DURANTE SUA TRAJETÓRIA DE ESCOLARIZAÇÃO

FONTE: A autora.

A grande maioria dos sujeitos, 9 dos 12, testemunhou/vivenciou violência em meio escolar: violência por professores contra alunos. Contudo, 7 sujeitos testemunharam e 2 sujeitos vivenciaram. Isso significa que a grande maioria de nossos entrevistados testemunhou e não sofreu, propriamente dizendo, algum tipo de violência durante sua história de escolarização. Apenas 3 futuros professores informaram que não testemunharam e não vivenciaram violência da escola. Note-se que é bastante modesto o número de sujeitos deste estudo que não se referiu a nenhuma forma de violência em meio escolar. No que se refere aos danos que são causados nos agentes que testemunham e/ou vivenciam violência da escola não há benefícios a computar em nenhuma dessas situações, pois o maior grupo de nossos sujeitos foi simbolicamente agredido quando testemunhou agressões a seus pares. Lembre-se de que o testemunho em questão contribui para a construção do conformismo lógico a que se refere Pierre Bourdieu (2011), por meio de Durkeim, no que diz respeito à construção da realidade.

Neste caso, especialmente, no que se refere à produção da cultura da violência apontada no Relatório NEV/USP (CARDIA, 2012). Assim, os 7 sujeitos que testemunharam ${ }^{5}$ são igualmente vítimas (como os dois que vivenciaram) e

${ }^{5}$ Esses sujeitos se referiram a várias agressões de professores contra alunos durante sua história de escolarização, o que dá volume aos malefícios causados nesses sujeitos por esses testemunhos. 
podem “crer", como os outros dois, que a agressão que testemunharam é legítima, sobretudo porque se trata de uma agressão cometida no âmbito de uma relação mediada por poder: professor e aluno. É exatamente esse jogo representacional, e relacional, da construção da realidade que nos preocupa demasiadamente: futuros professores estão expostos à violência da escola e construindo e relacionando representações sobre o que é legítimo nessa instituição no que diz respeito ao poder de dominação entre professor e aluno.

Ainda olhando para o Gráfico 2 e observando que a grande maioria desse grupo de futuros professores testemunhou/vivenciou violência da escola, o alerta que se coloca ganha em complexidade, pois há que se pensar sobre a produção/ reprodução da "cultura da violência", fartamente detalhada no Relatório NEV/ USP (CARDIA, 2012). Esse relatório nos dá a ordem de grandeza da problemática apresentada neste estudo: futuros professores que testemunharam e/ou vivenciaram violência em meio escolar podem reproduzi-la quando exercerem a profissão. Isto porque estamos pensando em agentes sociais objetivados socialmente e relacionalmente e não estamos trabalhando com a ideia de agentes especiais fora de contextos sociológicos reais. Vale dizer, então, que $75 \%$ dos nossos entrevistados de algum modo enfrentaram o respectivo fenômeno durante sua formação básica, quer seja como telespectador-vítima quer como vítima. A seguir, o próximo gráfico apresenta o conteúdo da "violência da escola" deste estudo.

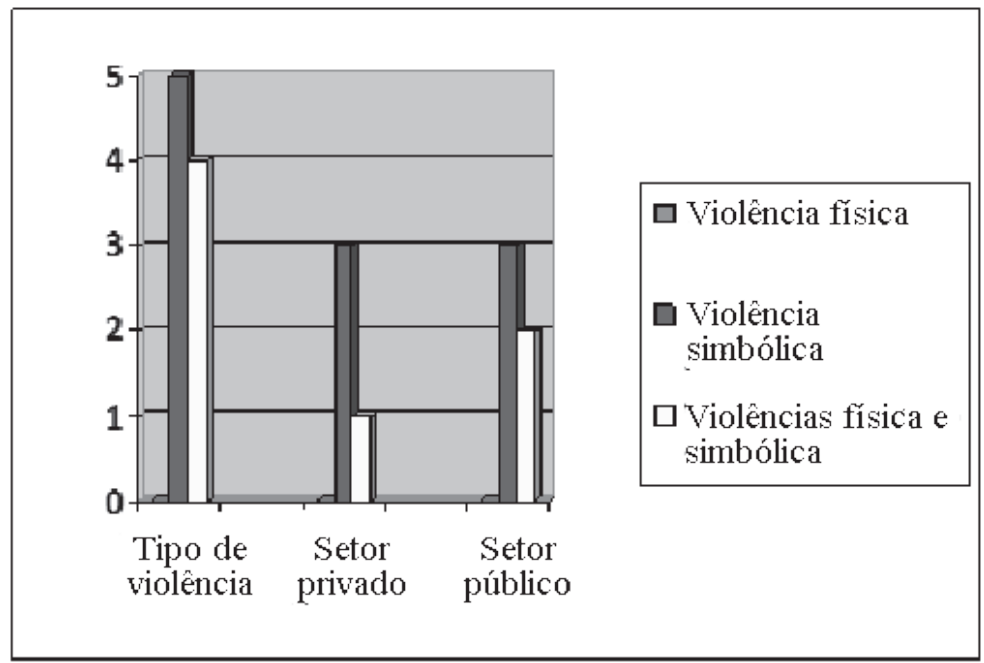

GRÁFICO 3 - TIPO DE VIOLÊNCIA TESTEMUNHADA/VIVENCIADA NO SETOR PÚBLICO E NO SETOR PRIVADO

FONTE: A autora. 
Desafortunadamente, o Gráfico 3 mostra a exuberância da categoria "violência da escola". Neste caso, o seu conteúdo está distribuído entre "violência física e simbólica" e "violência simbólica". No que se refere à composição do tipo "violência física e simbólica" (embora não estejam explicitados no gráfico) são atos de agressões físicas propriamente ditas: arrastar o aluno pelo braço para fora da sala de aula e chacoalhá-lo fisicamente. Essa situação, objetivada, agrega relacionalmente legitimidade no que diz respeito às ações no âmbito da sala de aula e, consequentemente, agrega representações sobre "habilidades" próprias do ofício docente. Estamos reiterando essa possibilidade porque nossos sujeitos são futuros professores. Ademais, o Relatório NEV/USP (CARDIA, 2012) aponta que:

A literatura sobre punição corporal revela ainda que pais que foram punidos fisicamente quando crianças tendem a repetir esta experiência, punindo fisicamente seus filhos. A este processo dá-se o nome de "ciclo de abusos", cuja existência tem sido reiteradamente demonstrada em investigações transgeracionais. Pesquisas como as de Knox (2010) e Maker (2005) demonstraram forte relação entre ser vítima de punição corporal na infância e a maior agressividade nos demais estágios de vida. O modelo explicativo desse processo seria a aprendizagem social. Por este modelo, as crianças, ao serem submetidas a castigos físicos, aprendem um repertório de ações agressivas que tendem a repetir no futuro (CARDIA, 2012, p. 86).

Vale lembrar que os sujeitos de nosso estudo, mesmo como testemunhas, se lembraram de ações dessa natureza ocorridas durante sua história de escolarização e a metodologia da coleta dos dados foi entrevistas não direcionadas para o tema violência em meio escolar. Não podemos deixar de repetir que os sujeitos em questão informaram muitos episódios testemunhados durante sua história de escolarização, denunciando pelo menos dois fatos: a violência de professores contra alunos é usual no ofício docente e a escola está funcionando como um lugar "pedagógico" para a legitimidade do "ciclo de abusos", como explica o relatório-fonte. Sem se esquecer de que os nossos sujeitos serão professores em breve. Nessa medida, a violência simbólica compõe a violência física por meio de palavras desrespeitosas e descabidas.

As agressões físicas reiteradas pelos nossos sujeitos sempre foram acompanhadas de ofensas verbais, como xingamentos: alunos burros, alunos animais e outras denominações afins. Partimos do pressuposto de que esses xingamentos 
são da mesma natureza do que se denomina "palavras de baixo calão". A esse respeito, o Relatório NEV/USP(CARDIA, 2012) traz uma profícua contribuição. Nele há a seguinte informação:

O uso de "palavras de baixo calão" continua a ser a forma de agressão mais frequente, principalmente entre os mais jovens. Enquanto entre os de maior idade 1,6 pessoas em cada 100 relatam ter sido vítimas deste tipo de agressão, entre os mais jovens a proporção é de 1 pessoa em cada 3 (CARDIA, 2012, p. 47).

Os dados apresentados no relatório em questão apontam para o fato de que crianças e jovens já são agentes que cometem agressões verbais na vida cotidiana, cometem e são acometidos. Nossos dados levam-nos a crer que a escola está contribuindo para legitimar esse comportamento fora e dentro da escola. Mais que isso, a escola está funcionando, devido à representação social que ainda tem, como uma "escola" da produção e reprodução da violência em consonância com a sociedade como um todo. A gravidade da problemática desta investigação reside, sobretudo, nessa possibilidade praticamente objetivada e relacionalmente pensada. Trata-se do poder simbólico que o poder também tem.

A propósito, a lógica da violência simbólica, segundo Bourdieu (2011), opera de tal modo que legitima ações, valores e práticas sociais. Quando um professor na posição de poder em relação ao aluno arrasta-o pelo braço dizendo que ele é burro - e isso é bastante praticado segundo nossos sujeitos -, contribui para a construção de representações acerca da pertinência da violência nas relações de poder especificamente no âmbito da escola. Esse ato em uma sala de aula atinge a todos: o aluno diretamente envolvido nessa ação e os que estão indiretamente envolvidos testemunhando o fato.

No que diz respeito à diferença que há nas ocorrências agressivas produzidas no setor público e no setor privado, ela está no fato de que no segundo o conteúdo da "violência da escola", isto é, "violência física e simbólica" é muito mais discreto do que no setor público, como mostra o Gráfico 3. Contudo, o conteúdo "violência simbólica" ocorre igualmente nos dois setores. É nessa medida que a operacionalidade do poder simbólico torna-se fértil para se pensar quais as razões da opacidade social da "violência da escola" no setor privado. Sem sombra de dúvidas, trata-se das questões de dominação entre classes. Ademais, de modo geral, a ocorrência da violência da escola no setor público e no setor privado quando se diz respeito à violência do professor contra o aluno, ainda, não é exaustivamente divulgada. A violência do aluno contra a escola e contra 
o professor é demasiadamente divulgada por meio de pesquisas e por meio da mídia $^{6}$. Contudo, tanto nas pesquisas quanto na mídia, trata-se majoritariamente do que ocorre na escola pública e não na escola privada.

Visivelmente essa exposição e esse ocultamento da violência da escola à luz dos respectivos setores de ensino estão diretamente relacionados às classes sociais que são usuárias de cada uma dessas instituições. A nosso juízo, a ideia de Pierre Bourdieu (2011) sobre o poder simbólico pode ser útil para explicar essa nuvem de fumaça em relação ao setor privado no que se refere à violência da escola e à, muitas vezes, exagerada exposição da violência da escola pública. Sobretudo, pela mídia.

Parece-nos que as frações de classes mais favorecidas "protegem sua escola" e as frações menos favorecidas não têm "poder" para fazer a mesma coisa com a escola que frequentam. Esse é o jogo de poder estabelecido objetivamente, relacionalmente e simbolicamente entre as classes sociais em sistemas capitalistas como é o caso brasileiro. Visando a maior explicitação possível da problemática violência da escola, mostramos abaixo os sentimentos desencadeados nos alunos pelas ações agressivas dos professores contra eles: tristeza, humilhação, medo e incômodo.

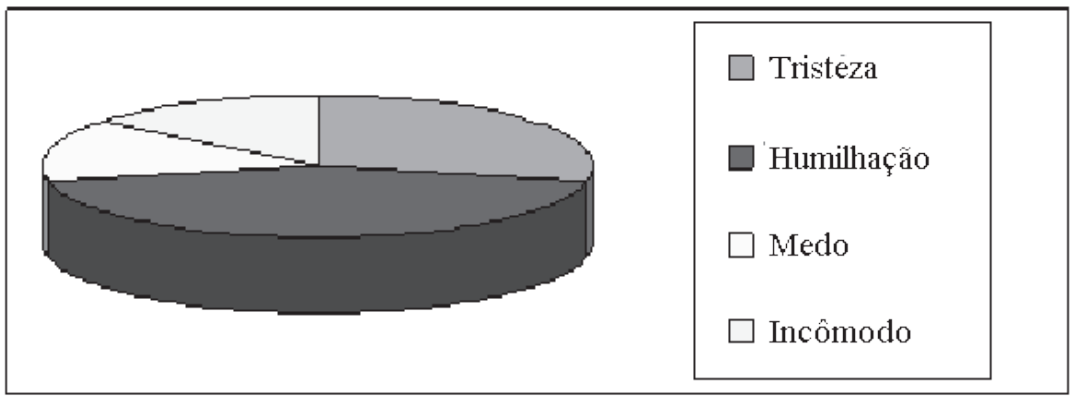

GRÁFICO 4 - SENTIMENTOS DESENCADEADOS PELAS SITUAÇÕES VIOLENTAS PRESENCIADAS/VIVENCIADAS DURANTE A HISTÓRIA DE ESCOLARIZAÇÃO DA ESCOLA BÁSICA

FONTE: A autora.

${ }^{6}$ Em estudo realizado por Scarlatto e Silva (2011), intitulado A violência por professores/as em escolas brasileiras: uma face do lado sombrio da cartografia escolar brasileira, mostra-se que de 219 pesquisas produzidas no campo educacional brasileiro sobre o fenômeno violência em meio escolar, de 2001 a 2009, apenas 11 são específicas sobre a violência de professores contra alunos. Isso poderia ser uma evidência de que não há violência de professores contra alunos. Contudo, os estudos realizados por Silva, M. da (2011,2012), Silva, A. (2011) e Diniz (2012) mostram o contrário disso: professores cometem muita violência contra alunos e a escola como instituição também. 
Observe que a humilhação ocupa a maior fatia do gráfico. Esse sentimento é bastante apropriado nas relações de poder vivenciadas nas sociedades de classes, facilitando a legitimação dessas práticas na representação de ambos os agentes: o dominador e o dominado. A tristeza ocupa o segundo lugar e, respectivamente, medo e incômodo, o terceiro e o quarto lugares. Podemos dizer que humilhação, medo e incômodo fazem parte do conteúdo das estratégias de legitimação do poder de um agente social sobre o outro de acordo com a posição que cada um ocupa, no campo a que pertence e na sociedade como um todo (BOURDIEU, 2011). Nessa medida o fenômeno da violência da escola representado pela violência de professores contra alunos pode ser, mesmo, considerado uma boa ferramenta à operacionalização das relações de poder, especialmente quando se trata do ofício docente. A exposição de futuros professores a essas práticas, bem como a incorporação da legitimidade destas, constitui referências imprescindíveis para se pensar a formação inicial de professores bem como a formação continuada.

\section{Considerações}

O conjunto de informações deste estudo no que diz respeito à produção da violência na sociedade como um todo e a produção da violência da escola em especial possibilitam-nos dizer que está havendo uma relação direta na produção da realidade brasileira cuja estruturação está sendo composta também pela violência de uns contra os outros. E isso está sendo operacionalizado por meio da produção e manutenção do ciclo de abusos e da produção da cultura da violência. Levando em conta que nosso interesse foca-se para a questão da violência da escola e que nossos sujeitos são futuros professores, o que podemos dizer, lamentavelmente, é que a formação inicial de professores e a formação continuada não têm dado a atenção que a ordem de grandeza do fenômeno está exigindo, tendo em vista, pelo menos, criar mecanismos teóricos e práticos que sejam adequados e eficazes para romper com o ciclo e a produção da cultura a que nos referimos.

Vale dizer, por exemplo, que o discreto número de pesquisas, como mencionamos, que tratam especificamente da violência do professor contra o aluno produzido no campo educacional brasileiro é uma amostra de que não estamos, a academia, levando em conta, guardadas as proporções, que a violência da escola não é produzida somente por um dos segmentos envolvidos no processo ensino/aprendizagem. Isso nos leva aos ciclos de abusos e à produção da cul- 
tura da violência em uma sociedade de classes cujo poder de uma classe sobre a outra e/ou de uma posição social sobre a outra costuram o consenso de que aqueles que ocupam a posição de dominado são consensualmente considerados responsáveis pela violência da escola. Isso é apenas uma ideia para a qual dedicaremos futuros investimentos.

É bem verdade que dados sobre violência do professor contra o aluno não são fáceis de serem coletados e necessitam de balizamentos teóricos férteis à explicação que demanda ética e muita seriedade social. Por outro lado, esse tipo de dado, miseravelmente, sofre cortes corporativistas, tendo em vista que se pode acreditar que se quer "mais um defeito" do e para o professorado brasileiro. Contudo, estamos nos referindo à produção de um fenômeno que está desde o descobrimento do Brasil arraigado e se arraigando em nossa sociedade, por isso a força dos ciclos de abusos e dos mecanismos da produção da violência na sociedade e na escola.

Os professores que agridem seus alunos também são vítimas do fenômeno, isto é, ocorre uma alta probabilidade de que eles tenham sido agredidos quer seja no âmbito da família, quer no da escola, durante o seu tempo de infância e juventude. O cerne da questão é este. Justamente por isso que alertamos na introdução deste artigo que ele não fosse lido com moralismos, corporativismos e reduções à complexidade do fenômeno violência em meio escolar. Por hora é só!

\section{REFERÊNCIAS}

BARDIN, Laurence. Análise de conteúdo. Lisboa: Edições 70, 1977.

BOURDIEU, P. O poder simbólico. 15. ed. Rio de Janeiro: Bertrand Brasil, 2011.

CARDIA, Nancy (Coord.). Pesquisa nacional, por amostragem domiciliar, sobre atitudes, normas culturais e valores em relação à violação de direitos humanos e violência: um estudo em 11 capitais de estado. São Paulo: Núcleo de Estudos da Violência da Universidade de São Paulo, 2012. Disponível em: $<$ http://www.nevusp.org/downloads/ down264.pdf $>$. Acesso em: 5/7/2012.

CHARLOT, Bernard. Violência na escola: como os sociólogos franceses abordam essa questão. Sociologias, Porto Alegre, n. 8, p. 432-443, jul./dez. 2002. Disponível em: <http:// www.scielo.br/scielo.php?script=sci_arttext\&pid=S1517-45222002000200016\&lng=p t\&nrm=iso $>$. Acesso em: 10/8/2012.

DEMARTINI, Z; ANTUNES, F. Magistério primário: profissão feminina, carreira masculina. Cadernos de Pesquisa, São Paulo, n. 86, p. 5-14, ago. 1993. 
DINIZ, J. A violência da escola na voz de futuros professores. São Paulo: FAPESP, 2012. Relatório de pesquisa para FAPESP processo $n^{\circ}$ 2010/11054-6.

RABELO, Amanda Oliveira; MARTINS, Antonio Maria. A mulher no magistério brasileiro: um histórico sobre a feminização do Magistério. In: CONGRESSO LUSO-BRASILEIRO DE HISTÓRIA DA EDUCAÇÃO, 4., 2010, Uberlândia. Anais... Aveiro: FCT, 2010. p. 6167-6176. Disponível em: <http://www.faced.ufu.br/colubhe06/anais/ arquivos/556AmandaO.Rabelo.pdf >. Acesso em: 13/11/2012.

SCARLATTO, E. C.; CARLINDO, E. P.; SILVA, M. da. Violências por professores/as contra seus/as alunos/as. Revista LEVS, Marília, v. 6, n. 6, p. 90-101, 2010.

SCARLATTO, E. C.; SILVA, M. da. A violência cometida por professores/as em escolas brasileiras: uma face do lado sombrio da cartografia escolar brasileira. In: CONGRESSO LUSO AFRO BRASILEIRO DE CIÊNCIAS SOCIAIS, 11., 2011, Salvador. Anais... Salvador: CONLAB, 2011. Disponível em: <http://www.xiconlab.eventos.dype.com. br/resources/anais/3/1307141352_ARQUIVO_SALVADOR_2011.pdf $>$. Acesso em: $12 / 12 / 2012$.

SILVA, A. G. Violência por professores e professoras na voz de suas vítimas: uma estrutura do habitus profissional em professores brasileiros. São Paulo: FAPESP, 2011. Relatório de pesquisa para FAPESP processo nº 2010/11054-6.

SILVA, M. da. Violência por professores e professoras na voz de suas vítimas: uma estrutura do habitus profissional em professores brasileiros. São Paulo: FAPESP, 2011. Relatório de pesquisa para FAPESP processo nº 2010/11054-6.

. A violência da escola na voz de futuros professores. São Paulo: FAPESP, 2012. Relatório de pesquisa para FAPESP processo n 2010/11054-6.

SILVA, M. da; CARLINDO, E. P.; SCARLATTO, E. C. Violência por professores e professoras na voz de suas vítimas: uma estrutura do habitus professoral de professores brasileiros. São Paulo: FAPESP, 2011. Relatório de pesquisa para FAPESP processo $\mathrm{n}^{\circ}$ 2010/11054-6.

SILVA, M. da; SCARLATTO, E. C. Violência em meio escolar no Brasil: uma alternativa formativa para professores e futuros professores. Revista Ibero-Americana de Estudos em Educação, Araraquara, v. 4, n. 3, p. 07-17, 2009.

WERLE, Flávia Obino Corrêa. Práticas de gestão e feminização do magistério. Cadernos de Pesquisa, São Paulo, v. 35, n. 126, p. 609-634, 2005.

Texto recebido em 03 de junho de 2013.

Texto aprovado em 04 de julho de 2013. 